\title{
SWOT analysis of the Shanxi agriculture intellectual property rights
}

\author{
SHI Xue-qiao \\ (College of Economics and Management, North University of China, Taiyuan 030051, China)
}

\begin{abstract}
In the development of agricultural intellectual property in Shanxi Province, obvious "advantages" including significant resources and a good foundation are accompanied by beneficial "opportunities”, i.e., Shanxi regards the development of distinctive agriculture and dominant agricultural products as an important direction for economic restructuring in agriculture, with unprecedented support. But, at the same time, "weaknesses" and "threats" thereof will be "fatal simultaneous bottlenecks". Shanxi provincial governments at all levels should "pave the way" for a positive policy and regulatory platform, exert the three effects of agricultural products in innovation, brand and the leading position, and constantly promote the development of agricultural intellectual property rights.
\end{abstract}

Key words: SWOT; agricultural intellectual property rights; geographical indications

\section{Raising the problem}

Central Rural Work Conference in 2010 proposed to "firmly strengthen the fundamental standpoint, i.e., the "three rural issues", and firmly grasp the important focal point, i.e., promoting the allocation of resources towards the rural areas”. In Shanxi Province’s Rural Work Conference, the general requirement for the provincial agricultural and rural work in 2010 was proposed to “... thoroughly implement the scientific concept of development, regard the urban and rural development as a fundamental requirement, and consider the development of modern agriculture as a major task". Distinct agricultural products possess comparative advantages and potential advantages. Agricultural intellectual property such as geographical indication protection of agricultural products is deeply linked with "three rural issues" (YIN, GUO \& GUO, 2007). How to promote the development of agricultural products through agricultural intellectual property has been a recent issue which Shanxi is facing currently. The paper makes an overall analysis of the current situation of Shanxi agricultural intellectual property rights using the SWOT method.

\section{SWOT analysis for agricultural intellectual property development in Shanxi}

\subsection{Strength}

\subsubsection{Obvious strengths in resources}

Shanxi Province is rich in distinctive agricultural products, and it is the most favorable area for development of intellectual agricultural property rights as it has an obvious advantage in resources. Shanxi Province's traditional agricultural products show the following three major features: Firstly, variety-According to a survey carried out by authorities, there are as many as 580 varieties of agricultural products; Secondly, wide distribution—agricultural products are widely distributed in virtually every county and city; Thirdly,

SHI Xue-qiao, professor, College of Economics and Management, North University of China; research fields: intellectual property rights and regional economic development, intellectual property rights and innovation. 
fruitfulness-According to statistics, in 2008, Shanxi Province had a total output of 3.4 billion kilograms of fruit, including apple production of 2.23 billion kilograms, ranking third all over the country; jujube 0.2 million kilograms, ranking third; Walnut 0.06 billion kilograms, ranking third as well.

The Shanxi livestock like meat, eggs and milk production have also had considerable share of the overall livestock products in the nation. ${ }^{1}$ In particular, the following 4 distinctive agricultural products have important positions in the domestic market.

(1) Grains. Statistically in 2006, 3.2481 million mu (15mu=1hectare) of foxtail millet area, ranked first in nation, with 381.9 thousand tons of production, ranked second in nation. As for sorghum, 578.3 thousand mu of area with 112 thousand tons of output, both ranked sixth in nation. Oats, millet, buckwheat and bean production are all topping the whole country. ${ }^{2}$

(2) Dried and fresh fruit. Shanxi is located within an optimum cultivation area for the production of jujube walnuts but also within an optimum ecological region for the production of high-quality apples and other dried fruits.

Moreover, Shanxi has stepped into the list of China's most important agricultural areas, and it is one of five main provinces for jujube production, which playing an important role in the country's production of jujube.

More than 80 out of the total of 111 counties covering jujube distribution, Linxian county, has the national largest production base, but also been named as the "Home of jujube" by the State Forestry Administration.

Fenyang city's annual walnut output exceeds 2,500 tons, ranking first across the nation, one of the largest distributing centers of walnuts with the largest export base.

Yuncheng city's juice production has reached 300 thousand tons, accounting for one quarter of that of the whole nation.

Linyi county has the world's largest production base of fruit juice concentrate with 10 million tons of annual output, accounting for the national $1 / 10$ and the world's $1 / 16 .^{3}$

(3) Vegetables. At the end of 2008, there were 18 counties with more than 100 thousand mu of annual vegetables planted in Shanxi Province, and 136 townships with more than 10 thousand mu of the annual vegetables planting. ${ }^{4}$

A number of varieties thereof are in a pivotal situation, such as asparagus. According to statistics, as of the end of 2009, Shanxi Province has developed an export asparagus planting area of up to 180 thousand mu, involving more than 20 cities and counties across the province, becoming the world's largest asparagus cultivation, production, processing and export base. Especially during the five-year period from 2003 to 2007, Shanxi asparagus maintained a good situation for production and exports, with an annual of 30 thousand-ton export volume, accounting over $40 \%$ of the national canned asparagus export volume. ${ }^{5}$

(4) Chinese herbal medicine. Due to Shanxi's complex topography, landforms, climate, hydrology and soil's conditions, it is a suitable place for the plantation of Chinese herbal medicines and has become China's major province in herbal medicine production. Shanxi's total amount of its resources and production thereof are both topping across the nation. The annual output of medicinal herbs such as codonopsis, astragalus, forsythia, huangqi,

\footnotetext{
${ }^{1}$ Shanxi distinctive agricultural products are rising. Shanxi Economic Daily, October 22, 2009.

2 LI, Y. Y.. (2007). How to get out of narrow lane for development for Shanxi grain. Shanxi Agriculture, 10, 23-25.

3 Retrieved from http://www.sxgov.cn.

${ }^{4}$ Retrieved from http://www.xinhuanews.com and Shanxi Daily, October 22, 2009.

${ }^{5}$ Retrieved from http://www.cqn.com.cn/.
} 
bupleurum, polygalaceae and anemarrhena covers 30\%-45\% of the state's total annual consumption.

\subsubsection{Good foundation for development}

Since 1990s, Shanxi Province has put the development of special agriculture as the main focus of the adjustment of the agricultural economic structure, and regarded grains, grazing livestock, fruits and vegetables as the four main characteristic industries, focusing on building three major advantageous agricultural areas: Yanmenguan ecological animal husbandry economic zone, Central-and southern-area pollution-free fruit and vegetable industry zone, and Mountainous-area cereals and dried fruits industry zone. In 2007, Shanxi Province established the "eleventh five-year plan on the development of processing industry of farming and animal products”, putting forward the idea of building nine main industrial chains for agriculture industrialization. In 2008, the Shanxi Provincial Party Committee proposed "Four Plans" and "Six Projects" to promote modern agriculture, vigorously implementing the leading enterprise incubation program, the key construction projects of leading enterprises. In 2007, Shanxi Province demonstration of base construction on advantageous agricultural products was officially launched, selecting 33 counties for key construction projects based on their natural resources, forming a series of characteristic farming and animal husbandry bases. Currently Shanxi Province has built a number of leading enterprises for agricultural product processing and characteristic agriculture base, initially forming the three major modern agriculture demonstration zones.

\subsection{Weakness}

Generally speaking, the situation of Shanxi agricultural intellectual property rights doesn't allow for much optimism.

2.2.1 Fewer number of agricultural intellectual property rights

Because geographical indication as intellectual property rights in agriculture is divided into 10 categories, and 307 items are related to agricultural products, accounting for $95 \%$ of the total, it is the intellectual property rights most closely linked with the "three rural issues". Let us take the geographical indication for an example, to compare the central six provinces (see Table 1).

Table 1 Comparison on geographical indication of central six provinces

\begin{tabular}{|l|c|c|c|c|c|c|}
\hline Province & Shanxi & Anhui & Henan & Hunan & Hubei & Jiangxi \\
\hline $\begin{array}{l}\text { General administration of quality supervision (377 } \\
\text { geography indications, July 2005-June 2009) }\end{array}$ & 7 & 7 & 20 & 11 & 28 & 14 \\
\hline $\begin{array}{l}\text { State Trademark Bureau (666 certification marks) } \\
\text { Ministry of Agriculture (360 geographical } \\
\text { indications for agricultural products) }\end{array}$ & 22 & 3 & 13 & 14 & 17 & 24 \\
\hline
\end{tabular}

Notes: As of June 2009, December 2009, June 2010 separately for geography indications, certification marks, geographical indications for agricultural products.

Date source: www.npgi.com.cn, www.sbj.saic.gov.cn, www.aqsc.gov.cn.

As can be seen from Table 1, except for the number of geographical indications of agricultural products in the central six provinces in the first, the other two are minimal. This is because the main advantages haven't been played out, while the disadvantages have exerted great adverse impact.

2.2.2 Single method for intellectual property protection

Shanxi's intellectual property protection in agricultural products in new plant varieties, trademarks, patents, trade secrets, firms and so on, is not enough. One reason for this is due to the agricultural products themselves. Agricultural production cannot be refined, hence the industry chain is not complete, and the complete intellectual 
property system is difficult to form. The other reason is the mindset of grassroots agricultural producers for intellectual property protection and an indifferent sense of rights.

\subsubsection{Few laws and regulations and inadequate support}

Shanxi Province has not introduced local policies and regulations with regards to protection of agricultural intellectual property, which will adversely affect its works on agricultural technology innovation and protection of agricultural intellectual property. Furthermore, there’s a lack of supporting policies for Shanxi's export enterprises on agricultural products from the national authorities and the provincial authority, apart from Shanxi Inspection and Quarantine Bureau.

\subsection{Opportunity}

Before obtaining intellectual property protection, agricultural products processing can only be in the hands of workshop stage. However, with agricultural trademarks, geographical indications and other intellectual property protection is expected to scale operations. Building integrated agricultural industry mode from planting, primary processing to manufacturing, optimizing agricultural trademarks and geographical indications, and strengthening the protection of new plant varieties, can promote the development of characteristic agriculture and ecological agriculture. In 2009, Shanxi Province promulgated the "Shanxi Provincial People’s Government Views on Making Agricultural Product Processing Enterprises Bigger and Stronger", implementing the "513 project", i.e., in accordance with the principle of provincial, municipal, and county levels overall planning, sub-level progress, supporting fiscal points, respectively selecting 50, 100, 300 leading enterprises as a provincial-level echelon with emphasized cultivating, a municipal-level echelon and a county-level echelon with nurturing and guidance, through supporting these enterprises, focusing on creating Shanxi Province's eight industrial chains such as food, livestock, dairy products, fruit, vegetables, potato, oil, Chinese herbal medicine. ${ }^{6}$ Shanxi's key points in restructuring plan for agricultural development are to develop Shanxi's distinctive agriculture and advantageous agricultural products, which will provide very favorable opportunities for agricultural growth.

\subsection{Threat}

As reckoned above, agricultural intellectual property is influenced by agricultural products, but factors influencing agricultural products exist in lots of aspects. The current financial crisis is curbing the healthy development of the entire economy, especially agricultural development. In international trade, many countries have raised the threshold for imports of Chinese agricultural products. For example, health standards and technical standards of the European Union and Japan were strict, even almost harsh. However, many agricultural products processing enterprises in Shanxi Province found that it is difficult to achieve their standards in health conditions and technologies in the short term. In domestic market, on the one hand, Food Safety Law coming into operation on June 1, 2009, puts forward higher requirements in food safety for provincial SMEs, while Shanxi enterprises in agricultural products processing, mainly SMEs, are undoubtedly facing fierce challenge; On the other hand, the rapid development of other province's distinctive agricultural products is bound to put pressure on Shanxi Province.

\section{Countermeasures to promote the development of Shanxi agricultural intellectual property rights}

According to the above analysis, we can see that Shanxi has favorable "opportunities" and obvious

\footnotetext{
${ }^{6}$ Retrieved from http://www.shanxinewsnet.com.
} 
"strengths" in development of agricultural intellectual property rights, but "weaknesses" and "threats" could be an adverse "bottleneck" for the development of agricultural intellectual property rights in Shanxi. We think that we should focus on "SO" strategy, complemented by WT strategy, expanding advantages, exploiting opportunities, overcoming weaknesses and eliminating threats. Through building a platform, making full use of the following three effects, we should constantly promote the development of Shanxi agricultural intellectual property rights.

\subsection{Building a platform}

The government must change its function, do a better job in planning, guidance, support and protection for agricultural intellectual property rights, and set up a platform for policies and regulations. First, we must publicize local policies or regulations on protection of agricultural intellectual property as soon as possible, such as regulations on protection of geographical indications, regulations of promotion of new plant varieties; Second, the government should give vigorous support and guidance. Works on protection of agricultural intellectual property have been started later than in developed provinces, with incomplete service system for intellectual property, and less guidance from governments. "Shanxi Province People’s Government’s View on Making Agricultural Product Processing Enterprises Bigger and Stronger” pointed out that 450 agricultural product processing enterprises will be especially supported in the financial capital, finance, tax and other key aspects, which will be the best agricultural policy platform, but the key issue is how to put the so-called "key support and preferential terms" into effect.

\subsection{Exerting the three effects}

(1) Innovation effect

The level of development of agricultural products in Shanxi Province presents "three more three less" features, i.e., more primary products, less processed goods, more traditional products, less innovative products, more single products, less derivatives, which is mainly due to low capability in technological innovation of the majority of agricultural processing enterprises in Shanxi Province and the low technical content of their products. First, we must rely on the relevant universities and institutes to do targeted R\&D on "513 project" on grain, livestock, dairy, fruits, vegetables, potatoes, oil, traditional Chinese medicine eight industry chains, products with urgent need to develop international markets such as asparagus tea, asparagus drinks, medicine and health products, or derivatives, to improve value-added products and recycling capabilities. Second, we must support the agricultural processing enterprises in Shanxi Province to set up R \& D institutions so that more and more enterprises can own independent intellectual property rights.

(2) Brand effect

Shanxi agricultural products suffer from lack of brands, even with rich types and large quantities. Although the asparagus industry in Shanxi Province has 10-year history, the asparagus processing companies are all foreign-invested enterprises, local enterprises are almost with no license, no international orders, no product brands, low economic efficiency. Up to January 2010, Shanxi Province has had only 7 national well-known trademarks relevant to agriculture out of 39. It is obvious that Shanxi hasn't yet exerted its competitive advantage and market advantage in distinctive agricultural products which derive from their famous features. Therefore, Shanxi should actively develop products with geographical indications, agricultural products trademarks and so on, create Shanxi's own brands in agricultural products, and change advantages in resources into that in brands and competition.

(3) Leading enterprises effect

According to statistics from the office of Shanxi agricultural industry, in 2008 agricultural products 
processing enterprises in Shanxi Province were up to a total of 3,836, with 43.9 billion yuan of assets and 39.8 billion yuan of sales income, of which 25 enterprises had investments of over 100 million yuan, less than 600 enterprises over 50 million yuan, and the majority were small-scale enterprises with annual sales income below 5 million yuan.

Overall, small quantity, small scale and separate layout are three obvious features of leading enterprises. Most of the agricultural exporting enterprises lack their own agricultural production bases, and their raw materials are mainly supplied by farmers. Therefore, we should focus on cultivating agricultural products processing enterprises, to promote small and medium agro-processing enterprises, and professional cooperative units. Shanxi Province has developed three-level overall planning (province-city-country), and worked out development goals to make 450 agricultural product processing enterprises bigger and stronger, and encourage resource-based enterprises to transform and absorb outer capitals, which is a very useful trial, but will take time to be tested.

\section{References:}

LIU, G.. (2008, December 21). Shanxi agricultural products breaking through international markets. Chinese Commercial New. WU, J. P.. (2009, April 28). Shanxi agricultural products export encountering four major "bottlenecks”. Shanxi Peasant News.

YAN, G. Z. \& WANG, F. H.. (2009). Shanxi implementing 513 project, promoting agricultural leading enterprises bigger and stronger. Retrieved October 30, 2009 from http://news.qq.com/a/20091030/001423.htm.

YIN, H. S., GUO, F. H. \& GUO, Z.. (2007). The current situation and strategy on Shanxi distinctive agricultural products. Journal of Shanxi Agricultural Science, 35(1), 8-10.

(Edited by Ruby and Chris)

\section{(continued from Page 58)}

\section{References:}

Barton, D. G.. (2004). Agricultural cooperatives: An American economic and management perspective. International Symposium on Institutional Arrangements and Legislative Issues of Farmer Cooperatives. May 13-18, 2004, Taizhou, Zhejiang, China.

GUAN, C. Y.. (2004). Selection of economic cooperative mode to develop villages, China Cooperative Economic, 4, 9-10.

Mackinnon, M. P. \& Ish, D.. (2004): A model of Government-stakeholder collaboration: New Canadian federal cooperative legislation. International Symposium on Institutional Arrangements and Legislative Issues of Farmer Cooperatives, May 13-18, Taizhou, Zhejiang, China.

Marion, B. W.. (1985). The organization and performance of the U.S food system. Lexington MA: Lexington books.

Poole, N. D., Gomis, D. C., Igual, J. \& Gimenez, F. V.. (1998). Formal contracts in fresh produce markets. Food Policy, 23(2), 131-142.

WANG, Z. B.. (2000). Agricultural management model and conversion tendency of developed countries. World Agriculture, 6, 3-5. WANG, Z.B.. (2002). Research on model of china agriculture management. China Scientific Culture Press, 130-140.

ZHANG, X. J.. (2001). Historical contribution of the Japanese Agricultural Association, existing problems and tendency. China Rural Economics, 3, 13-17. 